\title{
Energy Conservation Awareness Campaign Regarding Socially Marginalised People of India: A Case Study of Slum Areas
}

\author{
Alka Sharma Grover, Member, IACSIT, and Abhilaksh Grover
}

\begin{abstract}
Almost all the aspiring economies follow the same path during the development phase, i.e. cities getting transformed into mega cities, towns to cities and small hamlets to towns, inviting a mammoth transmigration of human resource. Unable to bear the expenses but certainly wanting a slice of the economy, rural migrants create clusters on the outskirts of the urbanized area, which are commonly called slums. Deprived of the amenities the dwellers do what comes most naturally to deprived humans, steal the resources such as power [electricity]. Therefore a study was conducted to understand the impact of this very important resource of power, needed so much for economic development, on the marginalized sections of the society in the periphery of Chandigarh. They were also given legal awareness regarding punishment for theft of electricity. The campaign was taken positively by the slum dwellers and authorities.
\end{abstract}

Index Terms-Conservation, energy, kundi connection, slum.

\section{INTRODUCTION}

India a developing country having under developed villages invites trans migration of human resource from villages to cities. Migrant population is making their homes on the outskirts of the urbanized areas, commonly called slums. The government is unwilling to provide amenities to the slum dwellers, as it chooses to deny or ignore the existence of these slums for as long as it can and considers it a slur on the aspect of governance and administration.

Thus deprived of the amenities the dwellers do what comes most naturally to deprived humans, steal the resources such as power. It was observed that, these dwellers indulge in theft of electricity by inserting a hook, directly on the transmission line, drawing power undetected by the authorities. A study was conducted on marginalized sections of the society in the periphery of Chandigarh .Such a process is commonly called the kundi connection [1] and is almost a common norm. It is known to the authorities but they can do little about it, for it is impossible to have 24 hour surveillance and there can be a possibility of a violent backlash. The theft therefore goes on unabated. One may question, what is the relevance of theft of power to conservation of energy? The answer lies in the simple

Manuscript received January 1, 2013; revised April 20, 2013.

F A. Alka Sharma Grover is with DAV College, Sector-10, and Chandigarh, India (e-mail: alkachemistry@hotmail.com).

S. B. Abhilaksh Grover is with Jyoti Sagar Associates, Sushant Lok 1, Gurgaon, India (e-mail: abhilakshgrover@gmail.com). proverb, 'A penny saved, is a penny earned.' Metered and regulated supply of electricity is accounted for and hence it can be conserved by sensitizing people about its use and by resorting to several other measures, which shall be dealt with later, but in the case of unregulated unaccounted power, such measures are meaningless and in fact it can be termed to be one single source of abuse of the process of conservation.

\section{OBJECTIVES OF THE CAMPAIGN}

An energy conservation awareness campaign regarding socially marginalized people was conducted in slum areas around the city of Chandigarh. The population has increased at least five folds since its inception and the migrants have been residing in slums. The slum population is 0.35 million in around 40 slums of Chandigarh. Of these 14 are being provided with electricity through private contractors and the rest are using loop/kundi connections. The city administration is trying various methods to overcome energy related problems but without making people aware of energy conservation nothing can be achieved. The main aim of the campaign was to have a mass effect of the poor citizens by reaching every home, street and every corner of the city, especially the migrant/poor population who are meeting the energy needs by loop electrical connections. It was seen that water crisis was another major problem being faced by the Chandigarh slum dwellers [2].

\section{Methodology}

This paper deals with the methodology and impact of energy conservation campaign on the people living in the slums. At present the Chandigarh Administration is suffering a loss of Rs.70 million every year from around 20,000 unauthorized loop connections [3]. Recently the Chandigarh administration has approved a plan where all the loop connections with the city slums would be regularized. The area under study has no electricity generation resource of its own but the demand of electricity goes upto $300 \mathrm{MW}$ in summers and administration is able to procure only around $265 \mathrm{MW}$ either by buying or borrowing from other states. It receives $67 \%$ electricity from the state of Punjab, 23\% from the State of Himachal Pradesh and 10\% from Dhulkot [4] An effort is towards making Chandigarh a solar city which might be completed by the year 2020. Energy Conservation awareness campaign was conducted in the following large slums of Chandigarh. 
- Bhaskar Colony, Sector 25 D, Chandigarh.

- Dharawa Village, Chandigarh.

- Janta Colony, Sector 25, Chandigarh.

A sample of 500 men and women was collected for the purpose and the campaign included

- Sensitization through interactive sessions

- Awareness about laws on electricity thefts

- Free distribution of handouts on energy saving tips

- Show of power point presentations on the status of electricity in Chandigarh

- Documentary viewing shows

- Questionnaires and Feed back forms.

\section{LEGAL AWARENESS}

Section 135 of the Electricity Act, 2003 lays down the offences related to electricity and provides for the corresponding penalties. Clause 1 of the section makes any dishonest act of using a loop connection which interferes with the accuracy of registration and calibration of the electric meter to be an offence. This offence carries a punishment of imprisonment for a maximum term of three years.

Certain observations have been made in this regard:

- The proposal of the government to allow loop connections/kundi connections with the idea of having common meters will indeed be in contravention of Section 135 of the Electricity Act, 2003.

- Since slums mushroom along the bigger towns and cities, unchecked, it might not be possible for the government to regulate the maximum number of users for a single meter.

- These loop connections have been a major cause for deaths and grievous injuries, there has been no proposal for the securing of wires. Allowing such a system will further aggravate chaos.

Since it has been pointed out that the act shall apply uniformly to everyone, it seems unfair that an industry indulging in the electricity theft will also get the same punishment as a slum dweller that uses the loop connection to achieve what he perceives to be his natural rights. The recourse that the government must take is make the citizen aware of the concept of energy conservation and provide captive power for earmarked areas.

\section{RESUlTS AND DISCUSSION}

The response of the campaign was amazing at the end despite the initial hesitation of the people to open up and interact.

\section{A. Level of Awareness}

Women showed a lot of interest in domestic energy conservation whereas men were more interested in energy conservation regarding modern gadgets and appliances. Fig. 1 presents pre interactive response for energy conservation.

\section{B. Response towards Wastage}

It was found that electricity was being wasted due to faulty circuits, not switching off fans and lights and electrical gadgets. Fig. 2 represents pre interactive response in terms of wastage of electricity.

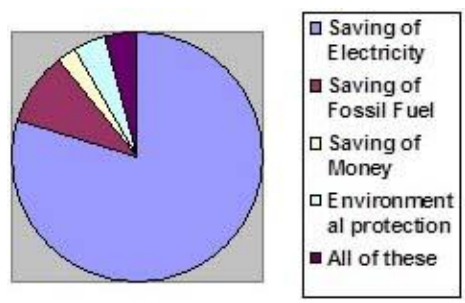

Fig. 1. Concept of energy conservation.

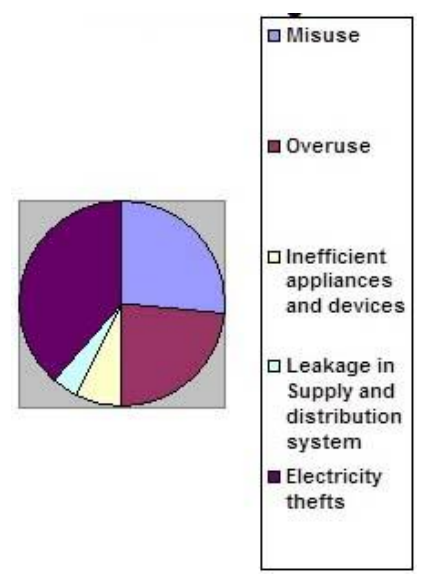

Fig. 2. Response towards storage.

\section{Awareness of Alternate Resources of Energy}

Very few people were using alternate energy sources and many had never heard of these energy resources. They were shown an exhibition on the use of solar equipment such as solar cookers and solar water heaters.

\section{Awareness about Government Initiatives and Electricity Theft Laws}

The people were not aware of the government subsidies involving solar appliances. It was suggested that Chandigarh Administration must adopt attractive ways of promotion and advertisements and the benefit should flow down to the poor people. Flyers and handouts were distributed.

\section{E. Ways and Means of Energy Conservation}

The PowerPoint presentations and documentary shows had a large impact on the audiences about the ways and means of energy conservation. They were shown the use of alternate uses of energy, construction of energy efficient buildings, enhancing green cover, use of Energy friendly appliances, use of CFL bulbs and half covered windows in summer months. Fig. 3 presents pre interactive response in terms of ways and means of energy conservation.

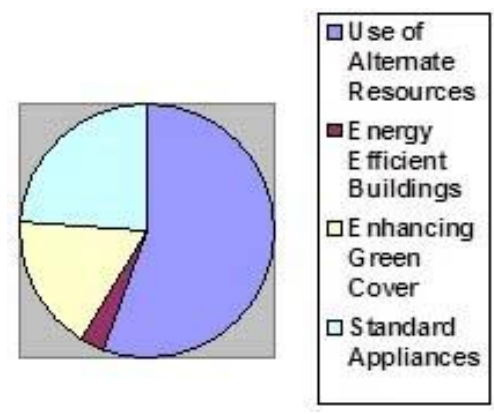

Fig. 3. Ways and means of energy conservation. 


\section{F. Role of Agencies in Energy Conservation}

It was found that the Non Governmental organizations were hardly playing a role as far as the energy conservation is concerned. Fig. 4 presents the pre interactive response of the people to the role of agencies in energy conservation.

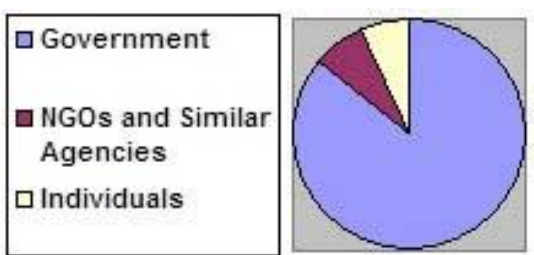

Fig. 4. Role of different agencies in energy conservation.

\section{CONCLUSION}

The energy awareness campaign to the socially deprived section of the society who is going to spread this message to each and every member of the society will surely leave a great impact in future. Such project and campaigns must be carried out frequently as the need of the hour is to change our mindset regarding energy conservation and sustainable development not only for the weaker sections of the society but for all.

\section{ACKNOWLEDGMENT}

Authors are thankful to IACSIT for their keen interest and kind offer to publish this paper. They also owe thanks to Chandigarh Administration, India and management of DAV College, Chandigarh, India for their support. They are also thankful to Justice Mahesh Grover, High Court, Chandigarh, India and Prof. K.K. Bhasin, Department of Chemistry, Panjab University, Chandigarh, India for their kind encouragement.

\section{REFERENCES}

[1] Kundi electricity connection is a famous Indian electricity theft technique, also called jugaad connection. [Online]. Available: http://www.kapurthalaonline.com
[2] Tribune News Service, Chandigarh, June 10, 2012.

[3] Tribune news Service, Chandigarh, March 12, 2012.

[4] Chandigarh hopes to become a Solar city in a decade, Indian Express, April 2, 2002.

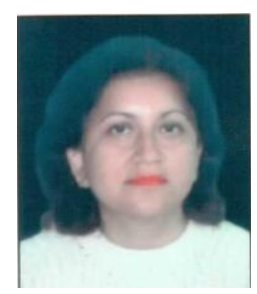

A. Alka Sharma Grover holds M.Sc. (Hons School) in chemistry and m.phil. (Analytical Chemistry) degrees obtained in the years 1979 and 1982 respectively from Panjab University, Chandigarh, India.

She is currently working as an ass. professor at DAV College, (Panjab University), Chandigarh, India, where she is specializes in teaching environmental chemistry. She authored MODIa text book of medical jurisprudence and toxicology, 24th ed., Nagpur, Madhya Pradesh, India: Lexis Nexis - Butterworth Wadhwa, 2011.

She is also pursuing his research on organochalcogenides. She has a recent research paper under publication in Journal of organomettalic chemistry by K.K. Bhasin, Ekta Arora, Alka S. Grover, Jyoti, H. Singh, S.K. Mehta, C. Jacob, "Synthesis and characterization of new 2- pyrimidyl chalcogen (S, Se, Te) compounds: X-ray crystal structure of bis $(4,6$ dimethyl-2-pyrimidyl) diselenide and 4,6-dimethyl-2- (phenylselanyl) pyrimidine" Journal of Organometallic Chemistry (In Press, Accepted Manuscript, Available online 26 February 2013).

Prof. Grover became a member of IACSIT (Registration no. 53122865K) in December 2012. She is actively evolved in various environmental projects sponsored by Department of Science and Technology, Chandigarh Administration, India specially regarding water quality, management, energy conservation and awareness campaigns on various social issues. She has earned distinction as convener of Eco Club, DAV College, Chandigarh, India.

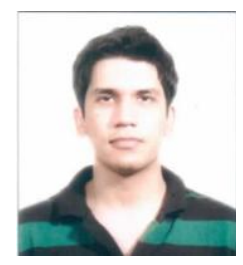

B. Abhilaksh Grover is 23. He was born on September 26, 1989 in the town of Chandigarh, India. He holds a B.A.llb (hons.) degree from NALSAR University of Law, Hyderabad (July, 2012). He is an admitted candidate at U.C. Berkeley for his masters in law for 2013-14.

$\mathrm{He}$ is currently working as an associate in $\mathrm{J}$ Sagar Associates, New Delhi focusing primarily on Litigation and Dispute Resolution. He has previously also been a part of Abhilaksh is a part of the projects practice of the firm focusing on Oil \& Gas, Electricity and Renewable Energy Project Development and Project Financing.

Mr. Grover has been also been a part of the NALSAR International Law Society and been active in moot court competitions, representing his university at the national (Bangalore, Chandigarh, Hyderabad) and international (Australia, Dubai) level. 